\title{
Trends of Web 2.0: Get close to Social Media
}

\author{
Zhu Mingfang ${ }^{1}$ Wang Qian ${ }^{2}$ \\ ${ }^{1}$ Shenzhen Tourism College of Jinan University,Shenzhen 518053; \\ ${ }^{2}$ School of Management,Jinan University,Guangzhou 510632
}

\begin{abstract}
The development of Web 2.0 will bring us into a new era. The advantage of Furthermore the development of Web 2.0 will give rise to the presence of social media: namely instant messages, social networking services, blog and microblogging which are the most important social media tools by now. Due to social media's characteristics of immediacy, openness, interoperability, decentralisation and other features, it has set off a wave of social media. This article aims to conduct a comprehensive review for social media which will exert certain influence on further studies of social media.
\end{abstract}

Keywords: Social Media review

\section{The Concept of Social Media}

The beginning of web 2.0 times promotes the development of social media tools, which not only have an effect of every profession but also promote the research on social media.Although leading scholars of web 2.0, like Stowe Boyd, Robert Scoble, Jay Rosen, Jeremiah Owyang, JD Lasica, Brian Solis etc,keep trying to define or redefine the concept of social media ,there's no decided definition with agreement from all parties till now.Social media as a group of internetbased service user interacting with other users online though different kinds of modes. It refers to writing or commenting blogs,sharing specific contents and communicating with friends over social network such as Facebook or Myspace(A. Kazım Kirtiş, Filiz Karahan, 2011).

The definition of social media should be the practical activities or behavior of people sharing messages, knowledge and opinions centered on internet communities(Safko and Brake,2009, s.6). The way how Wiki explains social media is more comprehensive. What social media describes is internet technology and time. People could use it to share ideas, experiences or expectations.Social media may contain different forms, including texts, pictures, audios and videos. These are all based on technology. Social media allows users communicating and interacting with each other. For example, blogs and the message board of Wiki.

There is no authoritative translation of social media in Chinese which reaches a consensus. This article tends to consider "She Jiao Mei Ti" as a proper translation, since the word "social" contains two essential meanings, namely society and the contacts among people in society. "She Jiao Mei Ti" shows the specific trait produced by writing, sharing commenting, discussion and communication that based on social contacts. Besides, it takes two sides of the conception into account,combining social contacts with the function of media. Art the definition we mentioned above are trying to prove that social media has managed to change the 
mode of dissemination of information from "one to mass" to "mass to mass". People could communicate or interact with others whenever and wherever they want. Every individual is possible to gain a dominant position in creating, passing or criticizing the information.

2. The difference of the content between domestic social media and foreign ones.

2.1The research of the role of social media in the government and nonprofit organizations.

(1)The foreign important research government organizations and non-profit organizations use social media to build and maintain public relations.

Social media are effectively utilized in public relations by non-profit organizations such as American Red Cross in the digital age (Briones \& Kuch, 2009). Many non-profit organizations are not using social media to their full potential. Some of them are not using Facebook, for example, to reach potential supporters (Waters, 2009).In the Internet environment,organizations public relationship includes five elements: commitment, (control mutuality, communality, trust, and satisfaction (Hallahan,2008). Government should utilize the contents of social media in order to strike a balance in assigning its resources to enhance the quality of service (Kavanaugh \& Fox, 2011). Sounman Hong, Daniel Nadler discover the use of social media by 2012 presidential candidates and its impact on candidate salience(Sounman Hong, Daniel Nadler,2012).

(2)The micro-blog has mentioned the main factors for improving the citizens participating the politics on behalf of the social media.

Micro-blog has overcome the limitation of the traditional media and its specialties shall promote the realization of Democratic Values(Ma Xiaojuan,2011).Chen and Cao have concluded the four tendencies for micro blog participating the politics(Chen Lidan and Cao Wenxing,2012). The development status of Chinese Government micro blog and the main problems existed based on the research with Guangdong Government micro blog as the object (Zhao Guohong, Yin Jiaxin, 2012).

In China it is rarely to make research on connecting the social media with public relationship. We can find that the timeliness, interactivity and participation of social media entitle itself the rights to establish and maintain the republic relationship from the overseas studies. We can pay attention to it. The scholars can put forward more constructive suggestions to help citizens take part in policies from politic, culture and other aspects.

\subsection{Analysis of the difference about the domestic and foreign research contents of social media in different areas.}

(1)Foreign social media is widely used in education

In the past few years, In the various fields of higher education,social media had become the new favorite(from politics to social sciences, to engineering and medicine).Marius Călin Popoiu and others raised the application of social media used in medical teaching (Marius Călin Popoiu ,2012). The mobile learning is through micro-blogging (Carmen Holotescu , Gabriela Grosseck, 2011). In higher education the use of social media to support student self-learning combines formal and informal learning personal learning environment which is very worth digging an educational pedagogy.Through literature review proved the correctness of this assertion (Nada Dabbagh, Anastasia Kitsantas, 2012). 
At home ,social media applications in education, although not consistent recognition, but have had exploration in this area.For example,Zhang Sheng, etc(2007)"Blog applications in higher education".Yu Lan(2010)"QQ-based platform for network-assisted teaching of English writing".Although the QQ, micro-blogging and other concept have begun to attract the attention of educational researchers, but not become a major trend.The reason for this is related to the development of domestic economic level, network equipment and facilities penetration is not high .In education and teaching, we can not use social media as an educational tool to popularize.Meanwhile, the domestic network control and some other objective reasons, can not be social media teaching in higher education as a major after-school education and teaching methods.

(2)By summing up the U.S. military on the use of social media to raise domestic military inspiration

From the psychological intelligence and information gathering, creating psychological warfare"opinion leaders",covert psychological warfare delivery information to enhance the role of psychological performance four aspects of social media use in psychological warfare ideas and methods (Wu Yinsheng,Mei Jianbing, 2011). Combining social media analysis of the characteristics of the U.S. Military to use social media the main intent of the implementation of strategic communications,social media strategy that the U.S. Military spread the basic characteristics (Zhang Xiyan, Yan Xingping, 2012).

(3)Domestic social media influence for media development

Social media and mobile GIS presents a convergence trend in the context of news reporting model should also be innovative
(Wang Yuming, 2012). The article is based on the U.S.news media mixed motives of in-depth analysis, from the macro and micro levels, Chinese news agency proposed countermeasures(Cui Bo, 2011).

\subsection{Research on social media marketing}

\subsubsection{Study on social media marketing abroad}

(1)Reasons for the promotion of social media application

In the context of economic crisis and economic recession, the social media will definitely get promoted because of its advantage in time, audiences, relations and the cost. The conclusion is drawn on the basis of data from big web site and the second-hand data statistics (A. plate Kazım Kirtiş, Filiz Karahan,2011).

(2)The social media's influence on fostering the customers' brand loyalty

This article "social media marketing's influence on brand loyalty" (2012) put forward five hypotheses which were tested through multiple regression analysis. By analyzing the data obtained from questionnaire, the conclusion was drawn that social media is the most favorable activity which can cultivate consumers' brand loyalty, following by the correlation of contents .By using structural equation model to study 441 respondents, found out that media brand community based on social media plays a significant role in the brand trust's translation into brand loyalty (Michel Laroche,2012).

(3)Strategy on marketing through building relationships with the consumers

By using some principles of operation and taking Yahoo for example, validation and $\mathrm{Z}$ inspection were made in order to verify that against the form of social media networks, opinion leaders played a 
significant role (Sang - Min Choi, Yu-Sub Han, 2013) . In the decreasing situation of the company's trust, enterprises are supposed to use a variety of ways to maintain public relations(Rawlins ,2009). By adopting the survey method, depth interview and content analysis and testing and interpreting the data, the conclusion is drawn that in order to testify whether high transparent information can be get in the social media(Marcia w. DiStaso, Denise Sevick Bortree,2012).

\subsubsection{Study on social media marketing domestic}

(1)On advertising marketing models in social media-study on social networks

Based on the analysis of advertising value of social networks, put forward the marketing mode by building up opinion leaders' guide(Xiao ZhiFen,2011). By comparing and elaborating viral advertising and the social media advertising, some strategies on how viral advertising can help improve the social media advertising are put forward(Yang Hui, 2009).

(2)The characters and value of social media in hope of offering marketing strategy for companies

2.4 Researching Methods of Social Media at Home and Abroad

Studies abroad often adopt quantitative analysis,which pays more attention to empirical research. They are more objectivity-oriented and considering continuous innovation of theories to be significant. However, domestic researches always combine exposition of a theory with

3. Evaluation at Domestic and Overseas Study on Social Media

In summary, domestic and foreign theoretical researches on social media have different emphasizes.
By making a summary of the characteristics of social media in 2012, Wang Lu, from Accenture China. Co , LTO, believed that we should make full use of the limitless possibilities offered by social media. Chen Shaojie, from Guang Zhou Shaoji Investment Consultation .co.LTD, being faced with the facts related to social media domestic and overseas. The promoted that it is necessary to take part in the social media marketing. Wu Siping claimed that tourism marketing need to change and innovate according to the situation of social media age.

Studies of social media marketing abroad is based on the researches of the complex relations among technology, namely web 2.0, social media and consumers. They try to find the reasons why social media marketing becomes so popularly used with the whole society as a background. While, what we do at home mostly is to analyze a certain case theoretically in order to give advices and suggestions to the company to make progress by using social media. This phenomenon may relate to the economic conditions of our country.

a certain case. They are short of quantitative analysis and empirical research which adopt mathematical model. This can make the results of researches irrational and subjective to certain degree. Therefore, to achieve more objective outcomes and more reliable theories, we should do more exploration and improvement about our researching methods.

Firstly, as for research content, because of the maturely developed foreign social technology and high usage rate of Internet, a variety of social media software has been developed and utilized more completely. Thus, overseas studies on social media are more extensive. Since China is 
in economic developing period, domestic researches are focus more on social media's function and economic values in marketing. In political aspect, foreign social media have fully played their role in communicating government and the public, building good relationship between them, as well as increasing government transparency and public trust in government, while in China, social media, for example Micro-blogging, are ways to raise the public's political powers. Because the characteristics, values and trends have not been fully understood, domestic researches are not thorough enough. The main reason for the difference in research contents lies in foreign extensive social media user groups and dispersed age distribution. For example, as one of the important social media, Twitter, is not only used by teenage and university students, but also used by 35 years-old and above adults whose annual income on average is $\$ 85,000$, according to Forester Research. Consequently, this trend leads many corporations to use Twitter, even including some big publisher (New York Times), retailors (Whole Foods Market) and Google itself. Due to such large user groups, various researches can acquire extensive data and case studies. On the contrary, in China, because of the limitations of user groups, it is difficult for Twitter to market. Basically, Twitter's users are university students who have lower income, thus its marketing is not successful. It takes a long way to go. The lack of research subjects limits such kind of researches.

Secondly, as for the researchers, In foreign,although there are six social media tools can be used, in fact, the practitioners of Public Relation prefer using social media While professionals like using traditional media (Eyrich, Padman, and Sweetser, 2008).In China, although there are rarely researches on the tendency of social media users, it is not difficult to find out that some practitioners pay great attention to social media, for instance, Wang Lu(Accenture China limited company),Chen Shaojie (Guangzhou Shaoji Investment consulting limited Company).Domestic researches can study on the application of social media as well as researcher groups in order to know more about the characteristics of social media's user groups, building the foundation for further researching.

Lastly, as for research trends, In contrast to domestic researches, which is relatively dispersed and lack depth study, foreign researches further expand this field and explore in depth. They study on the application of social media on various industries, further improving the application of social media and gradually forming a complete system. Domestic researchers on social media should form a completed research system, exploring theoretically and deep in different fields and levels. Research methods and angles can be further improved and innovated.

\section{References}

[1] Laura Malita," Social media time management tools and tips",Procedia Computer Science, 3, 747-753,2011.

[2]A. Kazım Kirtiş, Filiz Karahan , "To $\mathrm{Be}$ or Not to Be in Social Media Arena as the Most Cost-Efficient Marketing Strategy after the Global Recession. 7th International Strategic Management Conference," Procedia Social and Behavioral Sciences, 24 ,260-268,2011.

[3]Safko, L., \& D.K. Brake, The Social Media Bible. New Jersey: John Wiley \& Sons, Inc.2009

[4]http://en.wikipedia.org/wiki/Social_me $\underline{\text { dia }}$

[5]CAO Bo-in, "Social Media: Definition, History of Development,Features 
and Future-The Ambiguous Cognition of Social Media,"Journal of Hunan Radio \& Television University,PP.65-69,2011

[6]Zhang Tingting, "Case Study: A Probe into the English Language Teaching Strategies in a Microblogging Environment,"Modern "Educational Technology,pp.96-100,2011.

\section{[7]Rowena L. Briones, Beth} Kuch,Brooke Fisher Liu ,Yan Jin, “Keeping up with the digital age: How the American Red Cross uses social media to build relationships," Public Relations Review, 37,pp. 37-43,2011.

[8]Waters, R. D., Burnett, E., Lamm, A., \& Lucas, J. ,"Engaging stakeholders through social networking: How nonprofit organizations are using Facebook.,"Public Relations Review, 35(2), pp.102-106,2009.

[9]Hallahan,K.,Organizational-public relationships in cyberspace. In T. L. Hansen-Horn, \& B. D. Neff (Eds.), Public relations: From theory to practice Boston, MA: Pearson. pp.46-73,2008.

[10] Eyrich, N., Padman, M. L., \& Sweetser, K. D. , "PR practitioners' use of social media tools and communication technology,"Public Relations Review, 34(4),pp.412-414,2008.

[11]Andrea L. Kavanaugh , Edward A. Fox (2012). Social media use by government: From the routine to the cal .Government Information Quarterly, Volume 29, Issue 4, October 2012, Pages 480-491, Social Media in Government Selections from the 12th Annual International Conference on Digital Government Research (dg.o2011).

[12]Sounman Hong, Daniel Nadler, "Which candidates do the public discuss online in an election campaign?: The use of social media by 2012 presi- dential candidates and its impact on candidate salience.,"Government Information Quarterly,29,pp.455-461,2012.

[13]Marius Călin Popoiu, Gabriela Grosseck, Carmen Holotescu , "What do we know about the use of social media in medical education? " Procedia-Social and Behavioral Sciences, pp.2262 2266,2012.

[14]Carmen Holotescu, Gabriela rosseck, "Mobile learning through microblogging. "Procedia Social and Behavioral Sciences, pp.4-8,2011.

[15]Nada Dabbagh, Anastasia Kitsantas. "Personal Learning Environments, social media, and self-regulated learning: A natural formula for connecting formal and informal learning."Internet and Higher Education ,pp.3-8.

[16] Cui Bo,"Are the Social Media Changing the Way of News Communication? On the Hybrid Model of News Communication in the United States," Guo Ji Xin Wen Jie,pp.40-44,2011.

[17]A. Kazım Kirtiş, Filiz Karahan , "To Be or Not to Be in Social Media Arena as the Most Cost-Efficient Marketing Strategy after the Global Recession. 7th International Strategic Management Conference," Procedia Social and Behavioral Sciences ,pp.260-268,2011.

[18] İrem Eren Edoğmuş ,Mesut Çiçek, "The impact of social media marketing on brand loyalty . 8th International Strategic Management Conference," Procedia - Social and Behavioral Sciences, pp.1353-1360, 2012

[19] Michel Laroche, Mohammad Reza Habibi, Marie-Odile Richard, Ramesh Sankaranarayanan, "The effects of social media based brand communities on brand community markers, value creation practices, brand trust and brand 
ty, "Computers in Human Behavior, pp.1755-1767,2012.

[20]Sang-Min Choi, Yo-Sub Han ,"Representative reviewers for Internet social media, "Expert Systems with Applications ,pp.1274-1282,2013.

[21] Rawlins, B. , "Giving the emperor a mirror: Toward developing a stakeholder measurement of organizational transparency, "Journal of Public Relations Research, pp.71-99,2009.
[22] Marcia W. DiStaso, Denise Sevick Bortree ,"Multi-method analysis of transparency in social media practices: Survey, interviews and content analysis. "Public Relations Review,pp. 511-514,2012.

[23] Andreas M. Kaplan, Michael Haenlein (2011). The early bird catches the news: Nine things you should know about micro-blogging. Business Horizons ,54, 105-113. 